\title{
WHEN SPEED BREAKS THE SOUND BARRIER: THE EFFECT OF CUE HIERARCHY ON EXPECTED QUALITY AND PURCHASE INTENTIONS REGARDING LAPTOPS
}

\author{
Anthony Piermattéo ${ }^{\text {11}}{ }^{\mathbb{D}}$, Grégory Lo Monaco ${ }^{\text {b }}{ }^{\mathbb{D}}, \&$ Sylvain \\ Delouvée ${ }^{\mathrm{C} D}{ }^{2}$ \& 3
}

\author{
Université Catholique de Lille, Lille, France 4a ; Aix-Marseille Université, \\ Marseille, France ${ }^{\mathrm{b}}$; Université de Rennes, Rennes, France ${ }^{\mathrm{c}}$.
}

\begin{abstract}
A few taxonomies have been proposed to categorize the cues consumers use to assess the quality of a given product. However, these taxonomies do not take into account the possible hierarchy that may exist among these cues. Through three studies we tested a taxonomy based on the structural approach to social representations. This framework proposes a distinction between central and peripheral cues. The former would be essential whereas the latter would be less important in the process of conducting quality assessment or with regard to purchase intentions. Results show that, concerning purchase intentions, a good central feature can compensate for a poor peripheral feature while the converse is not possible. Moreover, this interaction effect is mediated by the perceived quality of the product.
\end{abstract}

Keywords:

cues; quality assessment; social representations; structural approach

\section{RÉSUMÉ}

Différentes taxonomies ont été proposées afin de catégoriser les indices utilisés par les consommateurs pour évaluer la qualité d'un produit. Toutefois, celles-ci ne tiennent pas compte de la hiérarchie pouvant exister entre ces indices. Au travers de trois études, cette contribution évalue une taxonomie fondée sur l'approche structurale des représentations sociales distinguant des indices centraux et périphériques. Les premiers seraient essentiels alors que les derniers joueraient un rôle secondaire dans l'évaluation de la qualité d'un produit ou concernant les intentions d'achat. Les résultats indiquent que, concernant les intentions d'achat, un point fort lié à une caractéristique centrale du produit peut compenser un point faible lié à une caractéristique périphérique tandis que l'inverse n'est pas possible. De plus cet effet d'interaction est médiatisé par la qualité perçue.

Mots clés :

indices ; évaluation de la qualité ; représentations sociales ; approche structurale

\footnotetext{
1 Correspondence about this article should be addressed to Anthony Piermattéo: anthony.piermatteo@gmail.com

2 Conflicts of Interest: The authors declare that the research was conducted in the absence of any commercial or financial relationships that could be construed as a potential conflict of interest.

3 This research has received financial support from Marsouin by the Regional Council of Brittany, France.

${ }^{4}$ Laboratoire ETHICS EA 7446.
} 
QUAND LA VITESSE FRANCHIT LE MUR DU SON : L'EFFET DE LA HIÉRARCHIE DES SIGNAUX SUR LA QUALITÉ ATTENDUE ET LES INTENTIONS D'ACHAT CONCERNANT LES ORDINATEURS PORTABLES

The social representation theory (Moscovici, 2008; for syntheses see Lo Monaco, Delouvée, \& Rateau, 2016; Sammut, Andreouli, Gaskell, \& Valsiner, 2015) proposes the idea that the perception of objects which are part of our reality can be defined as sets of opinions, attitudes and values constructed within the framework of social interactions. In this respect, they are guidelines for our judgments and our behaviors (Moscovici, 2008; Rateau, Moliner, Guimelli, \& Abric, 2011). Since its seminal formulation, this theory has triggered the development of several approaches among which features the structural approach, also known as the central core theory or even the structural theory (Abric, 2001; Galli, Fasanelli \& Schember, 2017; Moliner \& Abric, 2015; Rateau et al., 2011; Wolter, 2018). At the instigation of Michel (1999), this theory has led to a fertile connection with brand and more generally marketing studies.

Within the framework of this theory, Abric (2001) proposes considering a qualitative and structural distinction between two types of elements: central versus peripheral elements. Central elements compose the central core and generate and organize the socially constructed meanings concerning an object. Peripheral elements constitute a system of meanings dependent on the central core. Studies that have been conducted within the framework of this theory highlight theoretical, methodological and applied interests (Lo Monaco, Piermattéo, Rateau \& Tavani, 2017).

As we have previously said, since 1999, researchers have tackled the question of brand management and consumer behaviors (Lebrun, Souchet, \& Bouchet, 2013; Michel, 1999; Michel \& Donthu, 2014; Tafani, Haguel, \& Ménager, 2007). Several studies conducted within the framework of this theory have focused on the structural approach to social representations (SR) and the central core theory or on the socio-dynamic model (Doise, Clémence, \& Lorenzi-Cioldi, 1993). Moreover, within the framework of the structural theory, one can find information concerning the meaning-negotiability effect of the cognition composing the representational field (Katerelos, 2003). More precisely, the literature shows that the confirmation of a central element is able to compensate for the challenging of a peripheral one, but this phenomenon is not reciprocal (Katerelos, 2003). The objective of this study consists in testing this structure compensating-effect concerning quality cues in the context of the quality assessment of and purchasing intentions for a laptop. 
In order to assess the quality of a given product, consumers can use various cues such as brand (Erdem \& Swait, 1998; Germann, Kurth, \& Matthiesen, 2020), price (Batt \& Dean, 2000), advertising (Kirmani, 1997), and many others (Dawar \& Parker, 1994; Narwal \& Nayak, 2020).

The theoretical and methodological framework of the structural approach to social representations (Abric, 2001; Rateau et al., 2011; Rochira, Salvatore, Veltri, Redd, \& Lancia, 2020; Wolter, 2018) could allow us to study the organization of the cues used by consumers in relation to a given product (Michel \& Donthu, 2014). Indeed, according to this approach, the consumer categorizes cues on the basis of a dichotomy between central versus peripheral cues, as they would classify information related to a social object (this distinction can also be referred to as "core-periphery dichotomy", according to the recent study conducted by Ju \& Gluck, 2011; Ju \& O'Connor, 2013; Jung \& Pawlowski, 2014; Pawlowski \& Jung, 2015; Pawlowski, Kaganer, \& Cater, 2007). The central cues would be essential for recognizing the product as a quality product (i.e., "the good product"; Tafani, Haguel, \& Menager, 2007) whereas peripheral cues would be less important in the process of conducting quality evaluation or in relation to purchase intentions. In other words, the absence of, or the possible discrepancy between, a peripheral cue and the expectations of consumers, would not affect their evaluation of the product as a good one.

Thus, by drawing on the structural approach to SR, the aim of this study consists in focusing on the potential effect of cue hierarchy on product quality evaluation in general and purchase intentions by distinguishing central cues from peripheral cues. To this end, and through the example of the SR of laptops among a student sample, we will be particularly interested in the socially established knowledge that is linked to the products to be used as a cue for quality assessment.

\section{Structural Approach to Social Representations and Cue Hierarchy}

The structural approach to SR (Abric, 2001; Rateau et al., 2011, Wolter, 2018) focuses on social objects. On the other hand, in this study we are further concerned with the question of a product. However, even though the object of study is different in nature, we are dealing with the link established by a consumer between the feature and the product. This approach also proposes that all features do not carry the same weight and do not play the same role in consumers' product assessment and purchase intentions. More precisely, by their presence or absence, they may or may not meet the consumer's expectations. Indeed, beyond the presence of a feature, it is also its level of fit with 
expectations which will be predictive of the product quality assessment and purchase intentions.

In other words, the consumer would categorize the cues in accordance with a socio-cognitive structure distinguishing important and central cues from secondary and peripheral ones. Thus, they may organize cues like they organize beliefs or opinions related to social objects such as "work", "unemployment", "health", or "illness". Moreover, although these objects seem to be more anchored in a social context, we may wonder, from a socio-cognitive viewpoint and concerning the question of the products, whether the way of organizing cues in relation to products is dependent on the social context and/or social identity (Lo Monaco, Piermattéo, Guimelli, \& Abric, 2012), or even on communication with others and media exposure (e.g., advertising on TV, radio). For this purpose, it would be relevant to study the product as a social object and to consider that the methodologies associated with the structural approach to SR form an original and promising perspective. Indeed, according to Jung and Pawlowski (2014, p. 6) "the coreperiphery analysis of social representations offers a methodological alternative to research that explores users' understandings or perceptions of other important phenomena of importance in marketing research". Finally, consumers may rank the cues in two categories: the essential and central cues and the secondary and peripheral ones (Bordarie, 2019; Jung \& Pawlowski, 2014; Michel \& Donthu, 2014). Central cues would be essential for recognizing the object as an object characterized by a high level of quality, whereas peripheral cues would be secondary in conducting such an evaluation. On this basis, it is possible to perceive links between the structural approach to SR and the cue diagnosticity framework as this latter approach "views product quality assessment as a categorization process in which consumers use the available cues to assign a product to a specific quality category" (Purohit \& Srivastava, 2001, p. 125). Moreover, as these authors pointed out "A high-scope cue either "enables" or "disables" a low-scope cue by altering its diagnosticity, thus affecting the likelihood of it being used in product quality judgments" (Purohit \& Srivastava, 2001, p. 125). Consequently, we can assume that in comparison to peripheral cues, if the product fails on a central cue, the assessment in terms of overall quality and purchase intentions would be lower. In this regard, Katerelos (2003), working within the framework of the structural approach to SR, has highlighted the fact that an object can be recognized as an object of SR (in this case it was the SR of the university) when there is a negation of a peripheral characteristic (e.g., university is not pleasure) but confirmation of a central one. However, within the framework of such a "structural 
negotiability" the converse is not true. Indeed, the negation of a central characteristic cannot be offset by the confirmation of a peripheral one.

The present study proposes to tackle the question of the effect of cue hierarchy on perceived quality and purchase intentions with regard to laptops. On the basis of the structural approach to SR theory we can here consider that the nature of the cues may help to establish such a hierarchy. In this respect, taking into account the distinction between central and peripheral cues and the dynamics of structural negotiability, we can hypothesize that the cues used by individuals will not have the same effect on quality assessment and purchase intentions depending on their valence and their structural nature. Effectively, we first draw the hypothesis that positive cues (i.e., a good feature of the laptop) will lead to a better perceived quality and to stronger purchase intentions than negative cues (i.e., a poor feature of the laptop such as "poor performances" for example). Moreover, in line with the structural negotiability hypothesis, we expect an interaction effect between the valence of the cues and their structural nature. Within the framework of this interaction, we expect that a good central cue will lead to a better perceived quality and to stronger purchase intentions when it is associated with a good peripheral cue than when it is associated with a poor peripheral cue. In the same way, a poor central cue associated with a good peripheral cue would lead to a better perceived quality and to stronger purchase intentions than a poor central cue associated with a poor peripheral cue. However, a good central cue associated with a poor peripheral cue would lead to a better perceived quality and to stronger purchase intentions than a good peripheral cue associated with a poor central cue. Therefore, such an interaction indicates that, although a poor peripheral feature (e.g., the poor sound quality of a laptop) may be offset by a good central one (e.g., a good laptop speed), the converse is not possible.

\section{Overview}

In order to test these hypotheses, the mobilization of the theory of social representations implies the use of a specific methodology (Lo Monaco et al., 2017; Rochira et al., 2020) that consists of at least two sequential steps. Indeed, as we mentioned, the test of the structural negotiability hypothesis mainly relies on the comparison between central and peripheral cues associated with laptops. Such a comparison implies firstly the identification of these cues by collecting the various features related to laptops (Study 1). Then, in order to determine the structural status of these cues (e.g., central or peripheral), a second step is necessary (Study 2). On this occasion, the elements identified in Study 1 will be submitted to other participants who 
will then have to position themselves regarding these elements according to a methodology used in the field of social representations: the Test of Context Independence (TCI; Lo Monaco, Lheureux, \& Halimi-Falkowicz, 2008; Lo Monaco et al., 2017). These different elements will thus enable the third study to be carried out. This last study will focus more particularly on cue hierarchy through the evaluation of the structural negotiability of these cues within the framework of an experiment characterized by a between-subject design.

For all these three studies, the participants were all undergraduate students on a psychology course in a university in the south of France. Each study took place during courses where all the participants were invited to freely participate or between classes in various locations of the university. In this context, as the university of the leading authors does not have institutional review boards for psychology or social science research, we applied the 1964 Helsinki Declaration and its later amendments (2001), the ethical principles of the French Code of Ethics for Psychologists (2012), and the American Psychological Association Ethical Principles of Psychologists and Code of Conduct (2017). Participants were informed about the purpose of the study in a cover letter and were assured that their data would remain confidential. Participants had to give explicit consent to access the study. In addition, all research materials were uploaded to the Open Science Framework (https://osf.io/tf5uk/?view_only=9dce2d69f6cb498092f256d1cdf97f0f). Moreover, one should note that this sample was chosen for its specific suitability for the object under study (i.e., laptops). Indeed, laptops are widely used by students, especially in connection with their studies for which it is an important tool used for taking notes during classes or performing tasks assigned as part of their curriculum (Michaut \& Roche, 2017). As such, given the issues associated with this tool, and on the basis of the criteria mentioned by Moliner (1995), laptops could be the object of a specific social representation for this population. On this basis, there were only two inclusion criteria that characterized our sample: being a student and being over the age of 18. As participants were approached within a university, they all matched these prerequisites.

\section{Study 1: Cue Identification}

An initial study was conducted using the free ranked association method (Lo Monaco et al., 2017). Word association tasks are widely used in the field of SRs (Dany, Urdapilleta, \& Lo Monaco, 2015; Ernst-Vintila, Delouvée, \& Roland-Lévy, 2011; Jung 
\& Pawlowski, 2014, 2015; Lo Monaco et al., 2016; Mäkiniemi, Pirttilä-Backman, \& Pieri, 2011; Lebrun, 2014; Lo Monaco et al., 2017; Pozzi, Fattori, Bocchiaro, \& Alfieri, 2014). The aim of this study was to highlight the various features related to laptops. In fact, this method allows us to identify the different ways of regarding a product (i.e., in our case the laptop) through the verbal content that is linked to it.

\section{Method}

\section{Participants}

Sixty students $\left(M_{\text {age }}=21.9, \mathrm{SD}=2.91\right.$, age range: $18-35$ years $)$ were asked to participate in this first study. The sample was composed of 23 men and 37 women, $82 \%$ of whom owned a laptop.

\section{Materials and procedure}

Participants were asked to complete a three-stage questionnaire. Firstly, through a word association task, they were asked to associate the four words that came spontaneously to their mind when the inductor "the good laptop" was mentioned. Secondly, they were required to rank these associations from the most important (1) to the least important (4) in describing the inductor "the good laptop" (Lo Monaco et al., 2017). This second step allowed us to identify the most salient cues that determined the participants' perception of the "good laptop". Finally, they had to answer sociodemographic questions and to provide information concerning their habits in regard to laptops.

\section{Results}

On the basis of the free ranked association task, we obtained two types of information, the frequencies of the various content elements associated with the "good laptop" and also their mean importance, as the participants were required to rank their associations. Following the example of Lo Monaco et al. (2017), by combining these two types of information, we were able to create a $2 \times 2$ table in which each cell referred to a special class of the content composing the SR of a given object. More specifically, such a table (see Table 1) allowed us to determine which elements were potentially central and which elements were potentially peripheral. Effectively, although it gives us such information, the main purpose of the hierarchical evocations task was to collect the content of the SR, and only a second study using specific methods such as the TCI (Lo 
Monaco et al., 2008, 2017) or the challenge-attribute technique (Moliner, 2002) could give us reliable information concerning the structural status of the content composing a $\mathrm{SR}$, or in this case, concerning the cues related to the "good laptop".

Table 1.

Cues linked to the social representation of laptops as function of their average importance and frequency

\begin{tabular}{|c|c|c|c|c|c|c|c|}
\hline & & \multicolumn{6}{|c|}{ Average importance } \\
\hline & & \multicolumn{3}{|c|}{$<2.5$} & \multicolumn{3}{|c|}{$>2.5$} \\
\hline & \multirow{8}{*}{$>10 \%$} & & $\%$ & $M$ & & $\%$ & $M$ \\
\hline \multirow{9}{*}{ Frequency } & & Hard drive space & 55 & 2.15 & Small weight & 42 & 3.19 \\
\hline & & Speed & 48 & 2.21 & Design & 27 & 2.88 \\
\hline & & Battery life & 47 & 2.29 & Small size & 23 & 3.14 \\
\hline & & Performance & 38 & 2.00 & Sturdiness & 13 & 3.00 \\
\hline & & Ergonomic & 32 & 2.32 & Graphics board & 10 & 2.67 \\
\hline & & Economic & 20 & 2.50 & & & \\
\hline & & Reliable & 10 & 1.83 & & & \\
\hline & \multirow{2}{*}{$<10 \%$} & Compatibility & 8 & 2.20 & Sound quality & 8 & 3.00 \\
\hline & & Internet & 7 & 2.50 & Display size & 7 & 2.75 \\
\hline
\end{tabular}

The cues characterized by a frequency higher than $10 \%$ and a mean importance lower than 2.5 are considered as potentially central. These cues are associated the most with the "good laptop" and are considered as important by the participants. As potentially central, these cues are strongly linked to laptops. In other words, a "good laptop" that does not have one of these features would not be recognized as a good laptop. We can see here that most of these cues are focused on the aspects that facilitate the use of the laptop, which are linked to its ability to provide a good user experience. On the right of this first cell, this table presents the cues characterized by a high frequency and a low average importance; these cues are considered as potentially peripheral. These cues can be characterized by inter-individual variations and their absence - or a potential flaw characterizing such cues -will not significantly affect evaluations of the "good laptop". More precisely, a laptop which is very slow cannot be considered as a "good laptop", whereas if it is not small it could still be considered as a "good laptop". In opposition to the central cues, we can see that most of the cues of this cell do not refer to the "everyday use" of laptops but are rather focused on the external aspects of laptops, (e.g., "small", beautiful design"). The other cells of the table show other categories of cues. Among them are the cues considered as important, but by a small part of the sample. These cues may indicate that within our sample some of the participants may have a different SR of the "good laptop", an SR that would give priority to compatibility issues and the ability to connect to the Internet. The last cell - the cues characterized by a low importance and a low frequency - refers to the second periphery, these cues have the same characteristics 
as the other peripheral cues, but with a lower importance; they are also considered as peripheral.

To conclude, this initial study allowed us to identify the cues associated with the "good laptop" by the students composing our sample. However, despite the fact that the frequency and the average importance of each word associated with the laptops gave us a first glimpse of the hierarchy of the cues used by the participants, a second study was necessary to confirm their central or peripheral status.

\section{Study 2: Cue Hierarchy Identification}

On the basis of the cues highlighted through the first study, this second study aims to distinguish those that are central from those that are peripheral. This hierarchical distinction can be obtained using a specific technique: the TCI (Lo Monaco et al., 2008) which is one of the main methods for assessing the structural status of cognitions in the field of social representation studies (Moliner, 2016; Wachelke, 2012)

\section{Method}

\section{Participants}

Eighty students $\left(M_{\text {age }}=23.48, \mathrm{SD}=3.28\right.$, age range: $18-33$ years $)$ were asked to participate in this second study. The sample was composed of 41 men and 39 women, $83.75 \%$ of whom owned a laptop.

\section{Materials and procedure}

Participants had to complete a questionnaire using the TCI (Lo Monaco et al., 2008). The TCI aims to specify the trans-situational (i.e., for the central elements) or contingent (i.e., for the peripheral elements) character of representational elements. For example, participants were asked to answer the following item: "In your opinion, is a good laptop computer, a laptop computer that always offers, in every case, a good display quality". After reading each item, they were asked to answer using a 4-point Likert scale from 1 (Definitely not) to 4 (Definitely yes). If the majority of the participants (according to the "Dmax" Kolmogorov-Smirnov test; Kanji 1999) declared that a given characteristic was always, and in every case, linked to the object, then we could consider that it was central and so, essential in order to consider a laptop as a "good laptop". Conversely, if most of the participants considered that a given characteristic wasn't always, and in every 
case, linked to the object, then we could consider that characteristic as a peripheral one, and so, not determinant in the process of evaluating a laptop as a "good laptop".

\section{Results}

As shown by Table 2, we can see that the TCI does not confirm the central status of all the potentially central cues highlighted in the first study. This common result confirms the necessity of this kind of second study in order to confirm the results of the free ranked associations task (Lo Monaco et al., 2017). In the same way, we also see that solidity, which was considered as peripheral within the framework of the hierarchical evocations task, is now considered as central.

Consequently, the TCI allowed us to confirm the structural status of the cues composing the SR of the "good laptop". One notable fact is that the speed was considered as central by $100 \%$ of the participants. Therefore, on this basis, we chose this cue as the central one for testing structural negotiability in Study 3. As for the peripheral element, we chose the sound quality on the basis of the similarity between the nature of this cue and the nature of the "speed" cue. In fact, speed can also be considered as an intrinsic cue as it is directly related to the product itself. Moreover, unlike solidity or reliability, the speed can be evaluated only by using the product. So, in order to have two cues that would differ only in their structural status we chose a peripheral cue that encompassed these two characteristics. This was the case with sound quality and also with the resolution/graphic card. However, it seemed to us that the resolution/graphic card was a cue that could be mainly understood by the participants who had considerable knowledge about laptops whereas sound quality was a more common characteristic that could be understood by a larger part of our sample.

Table 2. 
Structural status of the cues linked to the representation of the laptops following the tci questionnaire

\begin{tabular}{lcc}
\hline Feature & TCI acceptation (\%) & Structural status \\
\hline Speed & 100 & Central \\
Hard drive space & 90 & Central \\
Reliability & 88,75 & Central \\
Sturdiness & 88,75 & Central \\
Battery life & 87,5 & Central \\
Performance & 87,5 & Central \\
Compatibility & 83,75 & Peripheral \\
Internet & 83,75 & Peripheral \\
Ergonomic & 82,5 & Peripheral \\
Small weight & 73,75 & Peripheral \\
Sound Quality & 72,5 & Peripheral \\
Economic & 70 & Peripheral \\
Graphics board & 56,25 & Peripheral \\
Design & 53,75 & Peripheral \\
Display size & 48,75 & Peripheral \\
Small size & 43,75 & Peripheral \\
\hline
\end{tabular}

Note. The structural status is diagnosed on the basis of the Kolmogorov-smirnov' test with a centrality threshold $(N=80)$ of $85 \%$.

\section{Study 3: Cue Hierarchy and Structural Negotiability}

This third study, based on the results of the two previous ones, aimed at testing our hypotheses concerning structural negotiability dynamics through an experimental setting that consisted in the presentation of short scenarios confronting central and peripheral cues characterized by diverging valences.

\section{Method}

\section{Participants and design}

One hundred and fifty-five students $\left(M_{\text {age }}=22.48, \mathrm{SD}=7.07\right.$, age range: $19-64$ years) were asked to participate in this experiment. They were randomly assigned to experimental conditions following a 2 (central cue: good vs. poor feature) x 2 (peripheral cue: good vs. poor feature) between-subjects factorial design. The randomization was implemented through the distribution of the questionnaires to the participants. More precisely, all the versions of the questionnaires belonging to each of the experimental conditions were mixed before distribution to the participants. The sample was composed of 26 men and 129 women, 94.84\% of whom owned a laptop. For the two first studies, participants were recruited in various locations of the university, and we paid attention to 
balance the sample in terms of gender. However, as the task of the third study required more time and a quiet environment, we chose to recruit the participants in the context of a psychology course. In this context, the male-female distribution reflects the general imbalance in gender distribution among French psychology students (Kamiejski, Guimond, De Oliveira, Er-Rafiy, \& Brauer, 2012). One should note that such a gender imbalance may not affect our result as our hypothesis regarding structural negotiability relies on socio-cognitive processes which are not thought to vary according to gender.

\section{Materials and procedure}

Participants were invited to take part in a study about laptops which consisted of a four-page questionnaire. As mentioned in the overview section, the whole questionnaire can be accessed online on the Open Science Framework. The experimental induction was based on short scenarios presented on the first page of this questionnaire and in which we manipulated the independent variables (see Appendix for an example). Participants were asked to imagine that they wanted to buy a laptop and had the opportunity to try it. In each scenario the central cue was induced by a reference to the speed of the laptop, as this characteristic was considered as a central one in the context of the TCI questionnaire (Study 2). The peripheral cue was induced by a reference to the sound quality. In each scenario, these cues could be presented either as a strong point or as a weakness revealed by the trial. Consequently, for example, the participants were exposed to a scenario that presented a trial that revealed a laptop with a good speed but a poor sound quality. Moreover, in order to ensure that there was no effect from the order of presentation of the central and peripheral cues, we counterbalanced them in all versions of the scenarios.

\section{Manipulation check}

Participants had to rate various characteristics of laptops on 11-point semantic differentials. Within this framework, characteristics such as performance could be rated on a scale from 0 (low performing) to 10 (high performing). In order to reduce the focus of the participants on the two chosen cues (i.e., speed and sound quality), we incorporated them in a list of characteristics to be assessed. These characteristics were all based on the results of the first study.

\section{Quality assessment}


Depending on the scenario, participants were asked to rate the laptop that was presented to them. More precisely, in order to obtain an evaluation of the overall quality, participants were asked first to rate whether they considered the presented laptop as a "good laptop" on a 6-point scale from 1 (not at all) to 6 (totally). Likewise, participants also had to estimate the quality of the presented laptop by positioning themselves on a visual analogue scale which consisted in a line drawn from a first anchor (very bad quality) to a second one (very good quality).

\section{Purchase intentions}

Then, as one can expect an effect of the product quality assessment and the perception of product value on purchase intentions (Sinrungtam, 2013), we measured participants' purchase intentions by asking them to rate on a visual analogue scale the likelihood of them buying the laptop that was presented to them (from "no chance at all" to "very likely").

\section{Inferred reliability}

In an exploratory way, we also asked the participants to evaluate through visual analogue scales (from $0 \%$ to $100 \%$ ) the probabilities of the performance of the presented laptop decreasing in the following days, weeks, months, in the next six months, in the next year, or never.

Finally, participants were also asked about their age, gender and their ownership of a laptop. Thus, as for data analysis, on the basis of our hypothesis, we expected to find --in the framework of factorial ANOVAs-- an interaction effect between central cue (good vs. poor) and peripheral cue (good vs. poor) variables for quality assessment as well as purchase intentions.

\section{Results}

\section{Manipulation check}

The two measures related to the evaluation of the manipulated features were submitted to a 2 (good central cue vs. poor central cue) x 2 (good peripheral cue vs. poor peripheral cue) factorial ANOVA. Concerning the "speed" cue, this analysis revealed a main effect of the central cue variable indicating that the participants effectively understood the induction as the laptop was judged faster when it was presented in such a 
way $(M=8.68, \mathrm{SD}=2.02)$ than when it was presented with speed issues $(M=0.91, \mathrm{SD}$ $=1.27), F(1,151)=821.02, p<.001, \eta p^{2}=.84$. Moreover, we noted that this evaluation of the speed was not affected by the manipulation of the peripheral cue as no significant main effect of the peripheral cue variable was observed, $F(1,151)=0.15, p=.697, \eta p^{2}$ $=.00$. Furthermore, no significant interaction between these two variables was found, $F(1,151)=1.06, p=.305, \eta p^{2}=.00$. Concerning the peripheral cue (i.e., the sound quality), the ANOVA revealed a main effect of the peripheral cue variable indicating that the sound quality of the laptop was judged as being better when this product was presented as characterized by a good sound quality $(M=8.80, \mathrm{SD}=1.86)$ than when it was presented with sound quality issues $(M=1.10, \mathrm{SD}=1.58), F(1,151)=769.00, p<.001$, $\eta p^{2}=.84$. Moreover, we noted that this evaluation of the sound quality was not affected by the manipulation of the central cue as no significant main effect of this variable was observed, $F(1,151)=0.19, p=.662, \eta p^{2}=.00$. In addition, no significant interaction between these two variables was found, $F(1,151)=1.86, p=.175, \eta p^{2}=.01$.

Therefore, these results indicate that the participants understood and took into account the pieces of information that were presented to them in order to conduct an evaluation of the laptop described in the scenarios.

\section{Quality assessment}

As mentioned above, two measures related to the assessment of the product's quality were proposed to the participants. Taking into account the strong correlation between these two measures, $r(155)=.85, p<.001$, we decided to standardize them and create a unique dependent variable that had been submitted to a factorial ANOVA between our two independent variables. This analysis first revealed a main effect of the central cue variable, indicating that participants formulated a better evaluation of the quality of the laptop when it was presented as fast $(M=0.62, \mathrm{SD}=0.83)$ than when it was presented as having speed issues, $(M=-0.61, \mathrm{SD}=0.65), F(1,151)=139.16, p<$ $.001, \eta \mathrm{p}^{2}=.48$. Moreover, we also observed a main effect of the peripheral cue variable, $F(1,151)=43.21, p<.001, \eta p^{2}=.22$. On the basis of this result it seems that participants considered the laptop as a better product when it was presented as having a good sound quality $(M=0.34, \mathrm{SD}=0.97)$ than when it was described as a laptop with a poor sound 
quality $(M=-0.34, \mathrm{SD}=0.83)$. Finally, the analysis also revealed a significant interaction between the two manipulated variables, $F(1,151)=4.86, p<.05, \eta p^{2}=.03$ (cf. figure 1 ).

Figure 1. Average quality assessment as function of the valence and the structural status of the cues. The error bars represent the standard error related to the means.

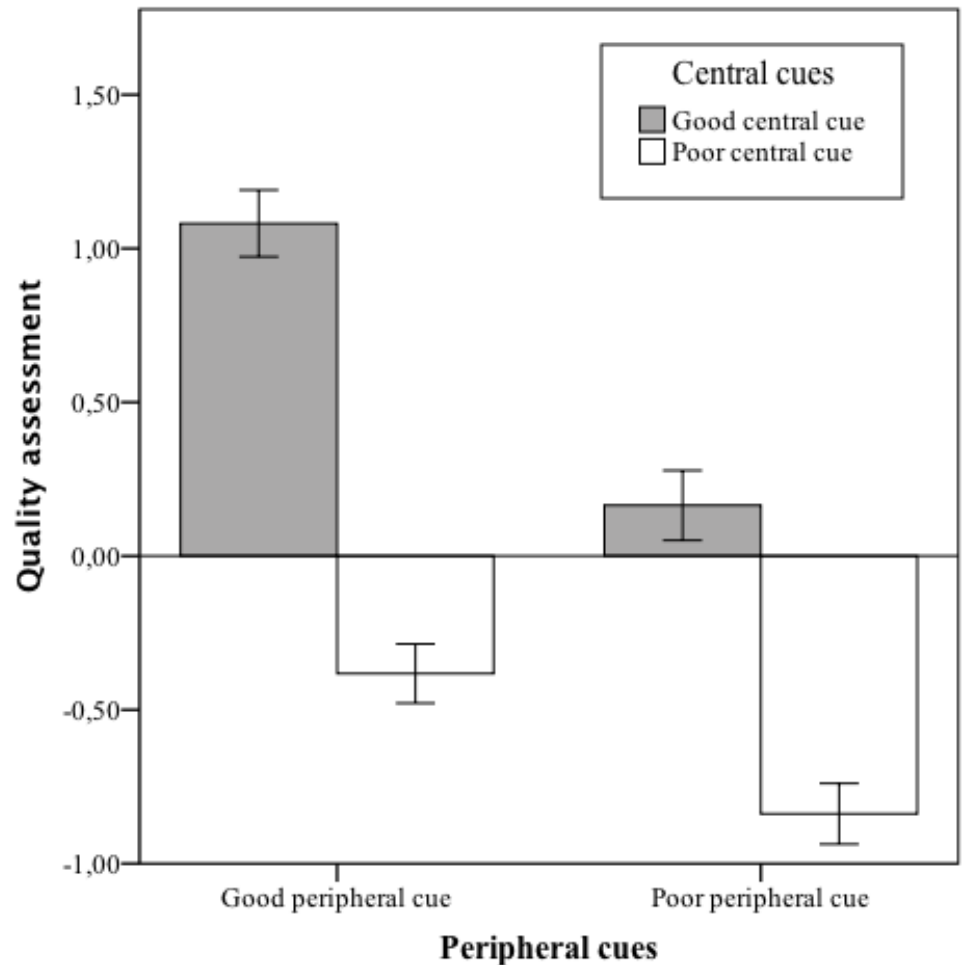

In the context of this interaction, and on the basis of our hypotheses, we carried out planned comparisons between the experimental conditions. The results of these analyses led us to observe that a laptop characterized by a good central feature was given a higher quality rating when this good central feature was combined with a good peripheral feature $(M=1.08, \mathrm{SD}=0.67)$ than when it was combined with a poor one $(M$ $=0.16, \mathrm{SD}=0.71), t(151)=6.19, p<.001, d=1.01$. In the same way, a laptop characterized by a poor central feature was given a better quality rating when this poor central feature was combined with a good peripheral one $(M=-0.38, \mathrm{SD}=0.60)$ than when it was associated with a poor one $(M=-0.84, \mathrm{SD}=0.62), t(151)=3.10, p<.01, d$ $=0.50$. Moreover, the most important contrast regarding our hypotheses indicated that a poor peripheral feature associated with a good central one led to better quality assessment $(M=0.16, \mathrm{SD}=0.71)$ than a poor central feature associated with a good peripheral one $(M=-0.38, \mathrm{SD}=0.60), t(151)=3.71, p<.001, d=0.60$. This last result confirms our hypothesis about structural negotiability, by showing that a positive central cue can offset a negative peripheral cue, and that, as expected, the converse is not possible. 


\section{Purchase intentions}

The factorial ANOVA conducted to measure purchase intentions also revealed a main effect of the central cue variable, $F(1,151)=109.74, p<.001, \eta p^{2}=.42$, of the peripheral cue variable, $F(1,151)=27.81, p<.001, \eta \mathrm{p}^{2}=.16$ and an interaction effect, $F(1,151)=10.53, p<.001, \eta p^{2}=.07$. Consequently, the results indicated that a laptop characterized by a good speed was the object of better purchase intentions $(M=3.31$, SD $=1.65)$ than a laptop characterized by a poor speed $(M=1.19, \mathrm{SD}=1.09)$. In the same way, the purchase intentions of the participants were higher when the laptop was characterized by a good sound quality $(M=2.77, \mathrm{SD}=1.82)$ than when it had a poor sound quality $(M=1.71, \mathrm{SD}=1.52)$.

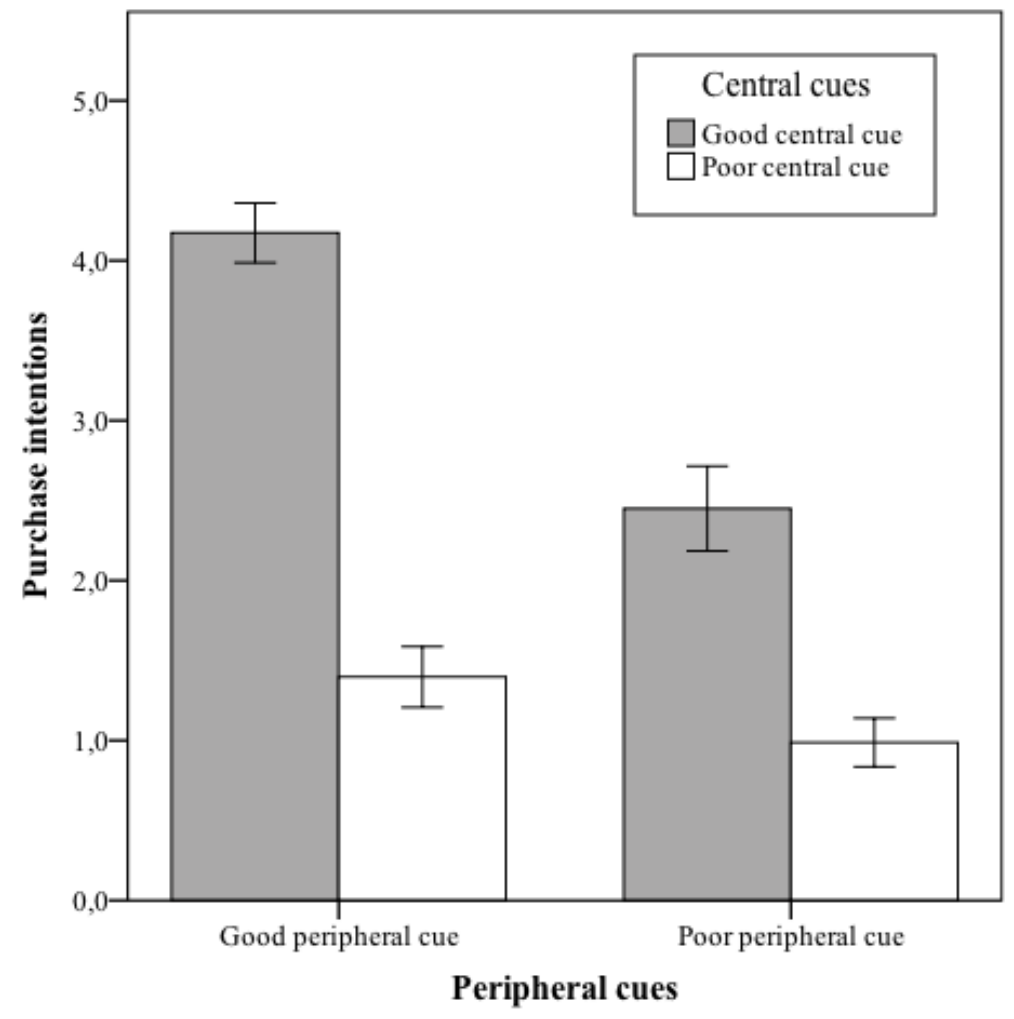

Figure 2. Average purchase intentions as function of the valence and the structural status of the cues. The error bars represent the standard error related to the means.

In the context of the interaction effect (cf. Figure 2), the contrast analysis indicated that participants confronted with a laptop characterized by a low speed had higher purchase intentions if this laptop was also characterized by a good sound quality $(M=$ $4.11, \mathrm{SD}=1.15)$ than if it was also characterized by a poor sound quality $(M=2.45, \mathrm{SD}$ $=1.64), t(151)=5.99, p<.001, d=0.97$. However, the second contrast did not reach significance, $t(151)=1.44, p=.15, d=0.23$, indicating that when the laptop was characterized by a poor speed, participants' purchase intentions did not differ as this 
laptop was also characterized by a good sound quality $(M=1.40, \mathrm{SD}=1.19)$, or a poor one $(M=0.99, \mathrm{SD}=0.95)$. This result, in principle, opposed to our hypothesis, seems finally in line with the structural negotiability theory as it shows that participants did not wish to purchase a laptop characterized by a poor speed (the mean-score was close to the anchor "No chance" on the purchase intentions scale) even if it was characterized by a good sound quality. Finally, as for the quality assessment measure, the last contrast showed results in line with our hypotheses as a laptop characterized by a good speed and a poor sound quality was the object of higher purchase intentions $(M=2.45, \mathrm{SD}=1.64)$ than a laptop characterized by a good sound quality and a poor speed $(M=1.40, \mathrm{SD}=$ 1.19).

Furthermore, one could expect that this interaction effect on purchase intentions would be mediated by the perceived quality, as a link between these two variables has been observed in the literature (Sinrungtam, 2013). Such an indirect effect can be considered as a mediated moderation (Muller, Judd, \& Yzerbyt, 2005). Consequently, on the basis of the procedure described by these authors, we performed a mediated moderation analysis that included the two manipulated independent variables, the perceived quality and purchase intentions. Within this framework, a first analysis showed that the central cue variable, $B=1.06, t(150)=10.48, p<.001, d=1.71$, the peripheral cue variable, $B=0.53, t(150)=5.27, p<.001, d=0.86$, and the interaction between these two variables, $B=0.33, t(150)=3.25, p=.001, d=0.53$, were significantly related to purchase intentions. Then, a second analysis performed on the proposed mediator (i.e., the perceived quality) also highlighted a significant effect of the central cue variable, $B=$ $0.62, t(151)=11.80, p<.001, d=1.92$, the peripheral cue variable, $B=0.34, t(151)=$ $6.57, p<.001, d=1.10$, and of the interaction between these two variables, $B=0.12$, $t(151)=2.21, p<.05, d=0.36$. Finally, a last analysis was conducted on purchase intentions, taking as independent variables the central cue variable, the peripheral cue variable, the interaction between these two variables and statistically controlling for the perceived quality and the interaction between perceived quality and the moderator (i.e., the central cue variable). The results of this last analysis indicated a significant effect of the moderator, $B=0.36, t(148)=3.16, p<.01, d=0.52$, and the mediator, $B=1.14$, $t(148)=8.93, p<.001, d=1.47$. However, neither the peripheral cue variable, $B=0.13$, $t(148)=1.41, p=.16, d=0.23$, nor the interaction between the peripheral cue variable and the central cue variable, $B=0.16, t(148)=1.74, p=.08, d=0.29$, nor even the interaction between the moderator and the mediator, $B=0.11, t(148)=0.82, p=.42, d=$ 0.13 , reached significance. 
Consequently, it appears that this pattern of results fits with the requirements proposed by Muller et al. (2005) in order to demonstrate a mediated moderation, and indicate a "full" mediated moderation as the moderation of the residual effect of the peripheral cue variable was no longer significant once the effects of the mediator and its interaction with the moderator were statistically controlled. Moreover, the Sobel test conducted on this mediated moderation was significant, thus confirming the presence of an indirect effect, $(\mathrm{z}=3.05, p<.01)$.

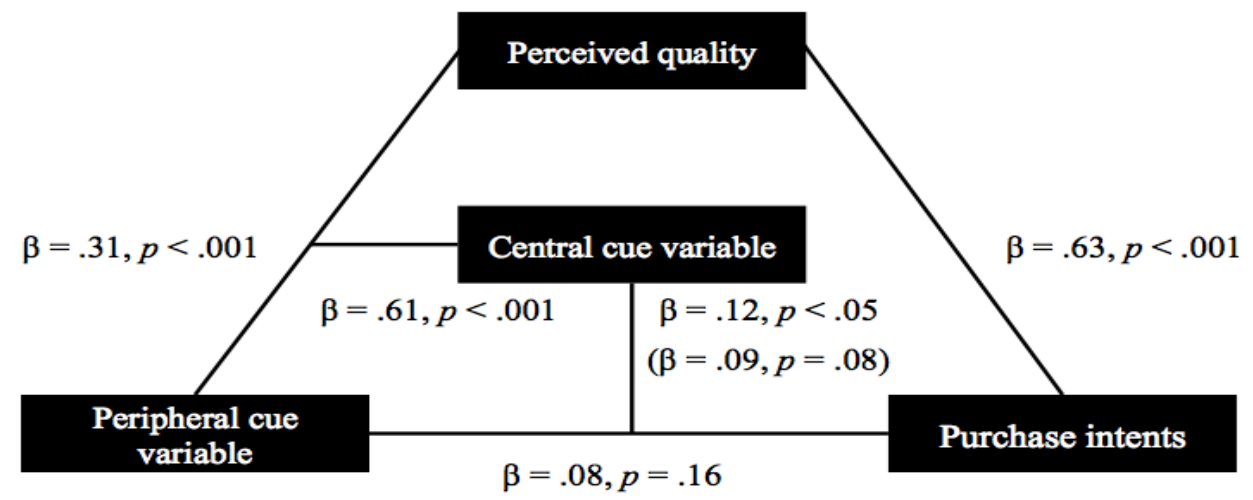

Figure 3. Mediated moderation between the cues based on their structural status, perceived quality and purchase intentions. The standardized beta coefficient in parentheses refers to the effects of the interaction between the peripheral cue variable and the central cue variable on purchase intentions once the mediator and its interaction with the moderator are statistically controlled.

As indicated by Figure 3, this mediated moderation indicates that (a) the effect of the peripheral cue variable on purchase intentions is moderated by the central cue variable, (b) this moderation effect on purchase intentions is mediated by the perceived quality. More concretely, the interpretation of the standardized coefficients shows that a good peripheral feature combined with a good central one induces a better perceived quality of the product, which in turn, improves purchase intentions.

\section{Inferred reliability}

On the basis of a reliability analysis we calculated a single measure of inferred reliability. As a reminder, this measure consisted of six questions evaluating the chances that the presented laptop could face a decrease in performance over the next days, weeks, 
months, after six months, after a year or never. However, the final Cronbach's alpha ( $\alpha=$ .80) led us to ignore the last item (i.e., measure of the chances that the performance of the laptop will never decrease) because it was characterized by a weak inter-item correlation $(r=.06)$. The composite score aggregating the five remaining items was submitted to a factorial ANOVA. This analysis only revealed a significant main effect of the central cue variable, $F(1,151)=11.77, p<.001, \eta p^{2}=.07$, indicating that participants considered that a laptop characterized by a good speed has less chance of seeing its performance decrease $(M=3.08, \mathrm{SD}=1.31)$ than a laptop characterized by a poor speed $(M=3.91$, $\mathrm{SD}=1.65)$. This effect, and the non-significance of the peripheral cue variable, seems to indicate that central cues are considered as more relevant with regard to the evaluation of the reliability of the product.

\section{Discussion}

The results of this research are, altogether, in line with our hypotheses. Indeed, we observed that taking into account the structural status of the cues related to laptops allows us to differentiate them from the viewpoint of their impact on perceived quality and purchase intentions. More precisely, based on our hypothesis concerning structural negotiability, we actually observed an interaction effect between the central and the peripheral cue variables indicating that, from the viewpoint of the perceived quality and purchase intentions related to the product, a good central feature can offset a poor peripheral one, while the converse is not possible. This effect of the structural status of the cues (i.e., central vs. peripheral) is in line with the moderating role of the structural status of cognitions, observed in the literature and coined SR-Structure Effect (SkandraniMarzouki, Lo Monaco, \& Marzouki, 2015). Moreover, these results thus replicate the results of Katerelos (2003) regarding structural negotiability in the context of an articulation between the fields of social representations and consumer behavior and go even further. Indeed, as we observed, the moderating role of the central cue variable seems to be part of a process characterized by an indirect effect on purchase intentions. More precisely, the evaluation of the quality of the product seems to be predicted by the interaction between the central and peripheral features and would in turn predict purchase intentions.

Thus, in line with the contributions of Lebrun et al. (2013), Michel (1999) or Michel and Donthu, (2014) these results highlight the relevance of employing SR-related theory and methodology in the perspective of consumer research. They also help to increase existing knowledge in this area by focusing on the dynamics associated with the 
structural status of cognitions (i.e., structural negotiability) and their impact on product evaluation. Indeed, in this context, the distinction between central and peripheral features allows us to predict the perceived quality and purchase intentions for the presented product. However, more generally, the relevance of drawing on SRs within such a context can be illustrated on several levels. Firstly, it is justified through the characteristics attributed to SRs since they are considered to determine behaviors related to the object (Piermattéo, Lo Monaco, \& Girandola, 2016; Rateau et al., 2011). Purchasing behavior and consumption can then be predicted and/or interpreted on the basis of the consideration of the SR to which they are related. On this basis, the distinction between central and peripheral cues, as we have seen, seems to specify and clarify these predictions and interpretations. We can also note that, as with the prediction of behavior, the methodologies we used in this research are consistent with the theoretical principles just mentioned. Thus, the collection of free ranked associations conducted within the framework of the first study also places SRs within a predictive perspective by linking that concept with the Expectancy-value model of Ajzen and Fishbein (1980). Indeed, according to this theory, the most prominent associations in the representational field seem to be those that maintain the most marked link with behaviors related to the object (or product) under consideration. Such behaviors may especially characterize choices and purchase decisions (Roininen, Arvola, \& Lähteenmäki, 2005).

Thus, our results are in line with the claim of Jung and Pawlowski $(2014$, p. 6) who state that "the core-periphery analysis of social representations offers a methodological alternative to research that explores users' understandings or perceptions of other important phenomena of importance in marketing research". Indeed, while the central (or core)-periphery dichotomy shares some similarities with other approaches (see notably the cue diagnosticity framework mobilized by Purohit \& Srivastava, 2001) one of its main advantages is to provide a specific methodological framework which allows us to distinguish which cues are considered as central and which ones are considered as peripheral (Lo Monaco et al., 2017, Rochira et al., 2020). Moreover, these methodologies rely directly on consumers' perceptions and not on an a priori classification created by experts and which may not accurately reflect one of the former (Löbbers, Lins, Kromat, Benlian, \& Sunyaev, 2020). Yet, a direct comparison between the central-periphery dichotomy and the other cue frameworks, notably regarding their ability to predict quality assessment and product choice, is yet to be carried out in order to properly distinguish the strengths and weaknesses of this new approach. 
However, although the results we observed are in line with our hypotheses and allow us to observe the differential impact of central and peripheral features, some limitations can be found. The first one is related to the gender imbalance which characterizes the sample of Study 3. Indeed, while the samples of Studies 1 and 2 were properly balanced, in order to fulfill the specific requirement of Study 3, its differing sample recruitment procedure led to a different sample composition in terms of gender. Yet, as we mentioned, this gender imbalance may not affect our result as our hypothesis regarding structural negotiability relies on socio-cognitive processes which are not thought to vary according to gender.

Another limitation is related to the variables taken into account. In particular, it appears that in the context of this research, variables, whose role seems to have however been critical, have not been taken into account. This is particularly the case with the participants' budget, the intended use of the product and the prior level of knowledge concerning the product (Bettman \& Park, 1980; Rao \& Monroe, 1988; Sullivan and Kim, 2018). Indeed, these elements can be considered as very important in the decision making process regarding the choice of a product. Consequently, through their impact on expectations, it seems possible to assume that these variables may have been able to modulate the observed effect of central and peripheral characteristics. However, in the light of the characteristics attributed to central and peripheral cues in the context of the theory of SR, we can assume that these variables are most likely to affect the impact of peripheral cues but would barely modify the moderating status of central cues. Indeed, as we mentioned above, central cues are characterized by insensitivity to context (Lo Monaco et al., 2008; Moliner, 2016; Wagner, Valencia, \& Elejabarrieta, 1996). In other words, these features are considered to be inseparable from the product, regardless of situations. In this regard, Wagner et al. (1996) pointed out that this attribute of central cues can be considered as one of the most important. In more concrete terms, this characteristic of central cues implies that for consumers, the speed of the computer remains a non-negotiable condition for product choice, whatever the budget, intended use or level of knowledge.

We also note that other variables may modulate the effect of the structural nature of cues on perceived product quality and purchase intentions. This could notably be the case with the brand. Indeed, several studies have emphasized the importance of the brand concerning the evaluation of the quality of a product (Dodds, Monroe, \& Grewal, 1991). In this context, brand awareness may be used as an indicator that allows participants to counter the negative impact of a poor product feature on the evaluation of the quality of 
the latter. Indeed, Cordell (1992), for example, showed that a strong brand reputation can limit the negative impact of the relocation of production, associated in the minds of consumers with a reduction in product quality. When these are linked to the distinction between central and peripheral cues, this raises the question of the hierarchy of these criteria. Indeed, although it seems possible to assume that a brand with a strong reputation could offset a poor peripheral feature, would it be the same for a poor central feature? Moreover, is brand awareness likely to be degraded by the presence of a poor central feature in some of its products? Or even more, could brand awareness maintain a high level of perceived quality in the case of a perceived reversibility of the poor feature by attributing it, for example, to an exceptional manufacturing fault that is not attributable to the brand as a whole? Such questions lead us to consider the links between the structural nature of cues and brand awareness as an interesting research agenda.

In addition, and in line with our previous example concerning the inferences that consumers may make, another research perspective drawing on the structural approach could be considered. Indeed, as Lynch and Srull (1982) pointed out, most purchase situations involve the confrontation of alternatives for which some information may be missing. In such a situation, the consumer may then be led to make inferences to reduce the uncertainty caused by this lack of information (Gunasti \& Ross, 2009). In this context, and according to these authors, these inferences can limit choice deferral or non-choice. However, although spontaneous inferences, characterized by similar effects, can be made on the basis of an earlier informational contribution such as exposure to a catalogue presenting the products (Gunasti \& Ross, 2009, Study 5), it is possible to consider that this informational input can be acquired in other ways.

Indeed, the issue that may represent the acquisition of certain products such as laptops can lead consumers to communicate with different sources. These communications, which will have the partial intention of reducing consumer uncertainty, could, through multiple influence processes, give rise to specific expectations concerning the product. Although, as we have seen in the context of this research, these expectations can be characterized by different structural statuses, it is also possible to consider that the social nature of the process that leads to their formation could also allow these latter to serve as a basis for a spontaneous inference to overcome some lack of information. More specifically, it would be possible to assume that a good central feature could lead to a spontaneous inference that would limit the negative impact of a missing feature on the product choice. However, it should be noted that, at this level, the structural status of the missing feature could also have a moderating effect. In this perspective, taking the 
structural approach to SR into account in future research could help to support Gunasti and Ross's conclusion (2009), which emphasized the need to find other ways to lead individuals to make spontaneous inferences. 


\section{References}

Abric, J.-C. (2001). A structural approach to social representations. In K. Deaux \& G. Philogène (Eds.), Representations of the social: bridging theoretical traditions (pp. 42-47). Malden: Blackwell Publishing.

Ajzen, I., \& Fishbein, M. (1980). Understanding attitudes and predicting behaviour. Engelwood Cliffs: Prentice-Hall.

Batt, P. J., \& Dean, A. (2000). Factors influencing the consumer's decision. Australian \& New Zealand Wine Industry Journal, 15(4), 534-41.

Bettman, J. R., \& Park, C. W. (1980). Effects of prior knowledge and experience and phase of the choice process on consumer decision processes: A protocol analysis. Journal of Consumer Research, 7(3), 234-248. http://dx.doi.org/10.1086/208812

Bordarie, J. (2019). Social representations and social marketing: Effectiveness of awareness campaigns on the representation of public policies?. International Journal of Nonprofit and Voluntary Sector Marketing, 24(2), e1633. http://doi.org/10.1002/nvsm.1633

Cordell, V. V. (1992). Effects of consumer preferences for foreign sourced products. Journal of International Business Studies, 23, 251-269. http://dx.doi.org/10.1057/palgrave.jibs.8490267

Dany, L., Urdapilleta, I., \& Lo Monaco, G. (2015). Free associations and social representations: some reflections on rank-frequency and importancefrequency methods. Quality \& Quantity, 49(2), 489-507. https://doi.org/10.1007/s11135-014-0005-Z

Dawar, N., \& Parker, P. (1994). Marketing universals: consumer use of brand name, price, physical appearance, and retailer reputation, as signals of product quality. Journal of Marketing Research, 58, 81-95. http://dx.doi.org/10.2307/1252271

Dodds, W. B., Monroe, K. B., \& Grewal, D. (1991). Effects of price, brand, and store information on buyers' product evaluations. Journal of Marketing Research, 28, 307-319. http://dx.doi.org/10.2307/3172866

Doise, W., Clémence, A., \& Lorenzi-Cioldi, F. (1993). The Quantitative analysis of social representations. Hemel Hempstead: Harvester Wheatsheaf.

Er-rafiy, A., \& Brauer, M. (2012). Increasing perceived variability reduces prejudice and discrimination: Theory and application. Social and Personality Psychology Compass, 6(12), 920- http://dx.doi.org/935. 10.1111/spc3.12000

Erdem, T., \& Swait, J. (1998). Brand equity as a signaling phenomenon. Journal of Consumer Psychology, 7, 131-157. http://dx.doi.org/10.1207/s15327663jcp0702_02

Ernst-Vintila, A., Delouvée, S., \& Roland-Lévy, C. (2011). Under threat. Lay thinking about terrorism and the three dimensional model of personal involvement: a social psychological analysis. Journal of Risk Research, 13, 297-325. http://doi.org/10.1080/13669877.2010.533468

Galli, I., Fasanelli, R., \& Schember, E. (2017). Iconographical stimuli as a creative approach for social representations. International E-Journal of Advances in Social Sciences, 3(8), 473-478. http://doi.org/10.18769/ijasos.336979

Germann, R., Kurth, L., \& Matthiesen, S. (2020). Disruptive factors in the evaluation of perceived quality aspects-consideration of the brand influence.

International Journal of Industrial Ergonomics, 76, 102931. http://doi.org/10.1016/j.ergon.2020.102931 
Gunasti, K., \& Ross, W. T. (2009). How inferences about missing attributes decrease the tendency to defer choice and increase purchase probability. Journal of Consumer Research, 35(5), 823-837. http://dx.doi.org/10.1086/593684

Ju, B., \& Gluck, M. (2011). Calibrating information users' views on relevance: A social representations approach. Journal of Information Science, 37(4), 429438. http://dx.doi.org/10.1177/0165551511412030

Ju, B., \& O'Connor, D. O. (2013). Beyond Categories: A Structural Analysis of the Social Representations of Information Users' Collective Perceptions on 'Relevance'. Journal of Information Science Theory and Practice, 1(2), 1635. http://dx.doi.org/10.1633/JISTaP.2013.1.2.2

Jung, Y., \& Pawlowski, S. (2015). The meaning of virtual entrepreneurship in social virtual worlds. Telematics and Informatics, 32(1), 193-203.

Jung, Y., \& Pawlowski, S. D. (2014). Understanding consumption in social virtual worlds: A sensemaking perspective on the consumption of virtual goods. Journal of Business Research, 67(10), 2231-2238. http://dx.doi.org/10.1016/j.jbusres.2014.01.002

Jung, Y., \& Pawlowski, S. D. (2014). Understanding consumption in social virtual worlds: A sensemaking perspective on the consumption of virtual goods. Journal of Business Research, 67(10), 2231-2238.

Kamiejski, R., Guimond, S., De Oliveira, P., Er-Rafiy, A., \& Brauer, M. (2012). Le modèle républicain d'intégration : implications pour la psychologie des relations entre groupes [The republican model of integration: implications for the psychology of intergroups relations]. L'Année Psychologique, 112, 51-85.

Kanji, G. K. (2006). 100 statistical tests. London: Sage.

Katerelos, I. D. (2003). Négociabilité argumentative intra-noyau: une etude exploratoire sur la structure des représentations sociales [Intra-core argumentative negotiability: an exploratory study on the structure of social representations]. Les Cahiers Internationaux de Psychologie Sociale, 60, 4049.

Kirmani, A. (1997). Advertising repetition as a signal of quality: If it's advertised so much, something must be wrong. Journal of Advertising, 26(3), 77-86. http://dx.doi.org/10.1080/00913367.1997.10673530

Lebrun, A. M. (2014). Representations of a destination city break. Analysis based on free associations. Journal of Travel \& Tourism Marketing, 31, 195-210. [LE? http://dx.doi.org/10.1080/10548408.2014.873312

Lebrun, A. M., Souchet, L., \& Bouchet, P. (2013). Social representations and brand positioning in the sporting goods market. European Sport Management Quarterly, 13(3), 358-379. http://dx.doi.org/10.1080/16184742.2013.787539

Lo Monaco, G., Delouvée, S., \& Rateau, P. (2016). Les représentations sociales. Théories, méthodes et applications [Social representations. Theories, methods and applications]. Bruxelles : de Boeck.

Lo Monaco, G., Lheureux, F., \& Halimi-Falkowicz, S. (2008). Le Test d'Indépendance au Contexte (TIC): une nouvelle technique d'étude de la structure représentationnelle [Test of Context Independence (TCI) and Structure of Social Representations]. Swiss Journal of Psychology, 67, 119123.

Lo Monaco, G., Piermattéo, A., Guimelli, C., \& Abric, J.-C. (2012). Questionnaire of characterization and correspondence factor analysis: a methodological contribution in the field of social representations. The Spanish Journal of Psychology, 15(3), 1233-1243. http://dx.doi.org/10.5209/rev_SJOP.2012.v15.n3.39410 
Lo Monaco, G., Piermattéo, A., Rateau, P., \& Tavani, J. L. (2017). Methods for studying the structure of social representations: a critical review and agenda for future research. Journal for the Theory of Social Behaviour, 47(3), 306331. http://dx.doi.org/10.1111/jtsb.12124

Löbbers, J., Lins, S., Kromat, T., Benlian, A., \& Sunyaev, A. (2020). A multiperspective lens on web assurance seals: contrasting vendors' intended and consumers' perceived effects. Electronic Commerce Research, 1-43. http://doi.org/0.1007/s10660-020-09415-2

Lynch, J. G., \& Srull, T. K. (1982). Memory and attentional factors in consumer choice: Concepts and research methods. Journal of Consumer Research, 9(1), 18-37. http://doi.org/10.1086/208893

Mäkiniemi, J.-P., Pirttilä-Backman, A.-M., \& Pieri, M. (2011). Ethical and unethical food. Social representations among Finnish, Danish and Italian students. Appetite, 56, 495-502. http://dx.doi.org/10.1016/j.appet.2011.01.023

Michaut, C., \& Roche, M. (2017). L'influence des usages numériques des étudiants sur la réussite universitaire [The influence of students' digital uses on academic success]. Revue internationale de pédagogie de l'enseignement supérieur, 33(1).

Michel, G. (1999). L'évolution des marques: approche par la théorie du noyau central [The evolution of brands through the theory of the central core]. Recherche et Applications en Marketing, 14(4), 32-53.

Michel, G., \& Donthu, N. (2014). Why negative brand extension evaluations do not always negatively affect the brand: The role of central and peripheral brand associations. Journal of Business Research, 67(12), 2611-2619. http://dx.doi.org/10.1016/j.jbusres.2014.03.020

Moliner, P. (2002). Ambiguous scenario and attribute challenge techniques. Social representations of the firm and the nurse. European Review of Applied Psychology, 52, 273-279.

Moliner, P. (2016). From Central Core Theory to Matrix Nucleus Theory. Papers on social representations, 25(2), 3-1.

Moliner, P., \& Abric J.-C. (2015). Central Core theory. In G. Sammut, E. Andreouli, G. Gaskell \& J. Valsiner (Eds.). The Cambridge Handbook of Social Representations (pp. 83-95). Cambridge: Cambridge University Press.

Moscovici, S. (2008). Psychoanalysis, its image and its public. Cambridge: Polity Press.

Muller, D., Judd, C. M., \& Yzerbyt, V. Y. (2005). When moderation is mediated and mediation is moderated. Journal of Personality and Social Psychology, 89(6), 852-863. http://dx.doi.org/10.1037/0022-3514.89.6.852

Narwal, P., \& Nayak, J. K. (2020). How consumers form product quality perceptions in absence of fixed posted prices: Interaction of product cues with seller reputation and third-party reviews. Journal of Retailing and Consumer Services, 52, 101924.

Pawlowski, S. D., \& Jung, Y. (2019). Social representations of cybersecurity by university students and implications for instructional design. Journal of Information Systems Education, 26(4), 3.

Pawlowski, S. D., Kaganer, E. A., \& Cater III, J. J. (2007). Focusing the research agenda on burnout in IT: social representations of burnout in the profession. European Journal of Information Systems, 16(5), 612-627. http://dx.doi.org/10.1057/palgrave.ejis.3000699

Piermattéo, A., Lo Monaco, G., \& Girandola, F. (2016). When commitment can be overturned: Anticipating recycling program dropouts through social 
representations. Environment and Behavior, 48(10), 1270-1291. https://doi.org/10.1177/0013916515597511

Pozzi, M., Fattori, F., Bocchiaro, P., \& Alfieri, S. (2014). Do the right thing! A study on social representation of obedience and disobedience. New Ideas in Psychology, 35, 18-27. http://dx.doi.org/j.newideapsych.2014.06.002

Purohit, D., \& Srivastava, J. (2001). Effect of manufacturer reputation, retailer reputation, and product warranty on consumer judgments of product quality: A cue diagnosticity framework. Journal of Consumer Psychology, 10(3), 123134. http://dx.doi.org/10.1207/s15327663jcp1003_1

Rao, A. R., \& Monroe, K. B. (1988). The moderating effect of prior knowledge on cue utilization in product evaluations. Journal of Consumer Research, 15(2), 253-264. http://dx.doi.org/10.1086/209162

Rateau, P., Moliner, P., Guimelli, C. \& Abric, J.-C. (2011). Social representation theory. In P. A. Van Lange, A. W. Kruglanski, \& E. T. Higgins (Eds.), Handbook of theories of social psychology (pp. 477-497). London: Sage.

Rochira, A., Salvatore, S., Veltri, G. A., Redd, R. R., \& Lancia, F. (2020). Theory and Method for the Analysis of Social Representations. In T. Mannarini, G. Veltri, \& S. Salvatore (Eds.), Media and Social Representations of Otherness (pp. 17-38). Cham: Springer.

Roininen, K., Arvola, A., \& Lähteenmäki, L. (2006). Exploring consumers' perceptions of local food with two different qualitative techniques: Laddering and word association. Food quality and preference, 17(1), 20-30. http://dx.doi.org/10.1016/j.foodqual.2005.04.012

Sammut, G., Andreouli, E., Gaskell, G., \& Valsiner, J. (2015). The Cambridge Handbook of Social Representations. Cambridge: Cambridge University Press.

Sinrungtam, W. (2013). Impact of country of origin dimensions on purchase intention of eco car. International Journal of Business and Management, 8 , 51-62. http://dx.doi.org/10.5539/ijbm.v8n11p51

Skandrani-Marzouki, I., Lo Monaco, G., \& Marzouki, Y. (2015). The effects of unconscious context on social representations: Evidence from the subliminal emotional priming paradigm. North American Journal of Psychology, 17(3), 509-524.

Sullivan, Y. W., \& Kim, D. J. (2018). Assessing the effects of consumers' product evaluations and trust on repurchase intention in e-commerce environments. International Journal of Information Management, 39, 199-219. http://dx.doi.org/10.1016/j.ijinfomgt.2017.12.008

Tafani, E., Haguel, V., \& Menager, A. (2007). Des images de marque aux représentations sociales des marques: une application au secteur de l'automobile [From brand image to social representations of brands: an application in the automobile sector]. Les Cahiers Internationaux de Psychologie Sociale, 73, 27-46.

Wagner, W., Valencia, J., \& Elejabarrieta, F. (1996). Relevance, discourse and the 'hot'stable core social representations-A structural analysis of word associations. British Journal of Social Psychology, 35(3), 331-351. http://dx.doi.org/10.1111/j.2044-8309.1996.tb01101.x

Wolter, R. (2018). The structural approach to social representations: Bridges between theory and methods. Psico-USF, 23(4), 621-631. http://dx.doi.org/10.1590/1413-82712018230403 


\section{APPENDIX}

Scenarios used as part of the third study:

Good central feature and good peripheral feature:

You wish to purchase a laptop and you have the chance to try it. After a few minutes, you realize that it is fast and that it has a good sound quality.

Poor central feature and good peripheral feature:

You wish to purchase a laptop and you have the chance to try it. After a few minutes, you realize that it is slow but that it has a good sound quality.

Good central feature and poor peripheral feature:

You wish to purchase a laptop and you have the chance to try it. After a few minutes, you realize that it is fast but that it has a poor sound quality.

Poor central feature and poor peripheral feature:

You wish to purchase a laptop and you have the chance to try it. After a few minutes, you realize that it is slow and that it has a poor sound quality. 